\title{
Effects of video interaction analysis training on nurse-patient communication in the care of the elderly
}

\author{
Wilma M.C.M. Caris-Verhallen MSc, $\mathrm{RN}^{\mathrm{a}}$, , Ada Kerkstra $\mathrm{PhD}^{\mathrm{a}}$, \\ Jozien M. Bensing $\mathrm{PhD}^{\mathrm{a}, \mathrm{b}}$, Mieke H.F. Grypdonck $\mathrm{PhD}^{\mathrm{c}}$ \\ ${ }^{a}$ Department of Nursing and Caring Research, Netherlands Institute of Primary Health Care, NIVEL, P.O. Box 1568, 3500 BN Utrecht, \\ The Netherlands \\ ${ }^{\mathrm{b}}$ Department of Clinical and Health Psychology, University of Utrecht, Utrecht, The Netherlands \\ ${ }^{\mathrm{c}}$ Department of Nursing Science, University of Utrecht, Utrecht, The Netherlands
}

Received 5 January 1999; received in revised form 20 June 1999; accepted 10 July 1999

\begin{abstract}
This paper describes an empirical evaluation of communication skills training for nurses in elderly care. The training programme was based on Video Interaction Analysis and aimed to improve nurses' communication skills such that they pay attention to patients' physical, social and emotional needs and support self care in elderly people. The effects of the training course were measured in an experimental and control group. They were rated by independent observers, by comparing videotapes of nursing encounters before and after training. Forty nurses participated in 316 videotaped nursing encounters. Multi-level analysis was used to take into account similarity among same nurse encounters. It was found that nurses who followed the training programme, provided the patients with more information about nursing and health topics. They also used more open-ended questions. In addition, they were rated as more involved, warmer and less patronizing. Due to limitations in the study design, it could not be demonstrated that these findings can entirely be ascribed to the training course. Further research, incorporating a randomized controlled design and larger sample sizes, is recommended to determine whether the results can be attributed to this specific type of training. (C) 2000 Elsevier Science Ireland Ltd. All rights reserved.
\end{abstract}

Keywords: Nurse-patient interaction; Communication training; Elderly care; Observation study

\section{Introduction}

It is generally agreed that the quality of nurse-

*Corresponding author. Tel.: + 31-302-729-725; fax: + 31302-729-729.

E-mail address: w.caris@nivel.nl (W.M.C.M. Caris-Verhallen) patient interaction is an important aspect in nursing the elderly. Yet, a variety of studies suggest that nurses overlook patients' social and emotional needs, focus on physical care instead and interact with their patients in a superficial way [1-5]. Apart from that, nurses seem to have adopted inappropriate communication styles [6]. Several studies into 
verbal communication show that nurses' conversation style is dependency creating, for instance in its use of 'secondary babytalk', which is defined as a set of accommodations including simplification and high and variable pitch, usually addressed to children, but also used in talking to the elderly [7-9]. Nurses also tend to exercise power in their communicative style and have a tendency to treat patients in a routine way without bothering to explain what they are doing. This may result in uncertainty in patients [10]. By explaining their behaviour and intentions, i.e. by formulating goals and saying what they are doing, nurses may reduce patients' feelings of uncertainty and thereby increase the quality of care [11].

In addition to verbal behaviour, a variety of studies have underscored the importance of adequate nonverbal behaviour. Nonverbal behaviour is the pre-eminent mode of building rapport with other persons and of conveying empathy and support [1216]. For instance looking, smiling and nodding at someone conveys interest and warmth $[17,18]$ and such gestures appear to contribute positively to others' perceptions of competence and credibility $[11,17,19]$. Besides, touch is also a very important aspect in establishing a relationship and can convey affection, care and comfort [20-22].

In response to the problems mentioned above, teaching communication skills is often promoted during and after the vocational training of nurses. However, simply giving nurses new protocols to follow is not enough to change patterns of interaction. Educational programmes should pay attention to both verbal and nonverbal communication in realistic situations [23]. For this reason, the use of video is often recommended in training health care professionals. It is interesting to note that video feedback is widely used in medical and GP training [24] but thus far it has not been very common in training nurses [25-27]. Recently, a group of nurses were trained using Video Interaction Analysis. The present study examines the effects of this training. The main research question to be addressed is:

What are the effects of a communication training, based on Video Interaction Analysis, on the communicative behaviour of nurses and patients in elderly care?

\section{Communication training}

The general aims of the training programme were to improve nurses' communication skills such that they pay attention to patients physical and social needs, facilitate selfcare in elderly patients and support them in finding their own solutions to their problems, in stead of giving the usual solutions from the professional vantage point [28].

Training focused on:

- Development of nurses' awareness of the physical, social and emotional needs of the elderly.

- Verbal communication techniques, such as, 'structuring', 'exploring patients ideas and opinions'.

- Enhancing patients' feelings of competence, by supporting them in finding their own answers. This requires nurses to show verbal attentiveness (paraphrasing and encouraging utterances like 'uhm's' and 'ah's') and help patients to explore the topic by means of open-ended questions (What did you think the solution was? What had you tried before? etc.).

- Nonverbal behaviours, such as 'looking at the patient while listening', stimulating the patients talk by 'head nodding' and 'forward leaning' as a sign of attention.

An important part of the training was dedicated to Video Interaction Analysis sessions in which pairs of trainees, guided by their trainer, watched and discussed videotapes of their own performance during nursing encounters.

In its entirety, the communication skills training programme combined:

- A 2-day introductory course, with a theoretical introduction on communication in nursing and the ageing adult, an explanation of the Video Interaction Analysis method and communication practice during role-play presentations with nursepatient interactions. In the role-play, patients were simulated by actors.

- Six small group sessions in which two trainees, guided by the trainer, analysed and discussed their own videotaped nursing encounters. During these sessions, three types of learning processes were 
supposed to take place: natural learning from the trainee's own review of performance on tape, peer comments and trainer feedback.

- Homework: the sessions alternated at 6-week intervals in which trainees practised the application of what they had learned. They also prepared the next Video Interaction Analysis session by recording a nursing encounter on video, which they had to analyse individually in advance.

- At the end of the course, there was a plenary meeting with the trainees, who participated in the introductory course. During the meeting, experiences were discussed and the course was evaluated with respect to its structure, process and personal results.

In terms of the aims of the training, trainees were expected to pay more attention to both the physical and social needs of patients, to be more supportive, less dominant, to disagree less and show more empathy. Trainees were also expected to demonstrate more rapport-building nonverbal behaviour, such as patient-directed eye gaze, affirmative nodding, smiling, leaning forward, and touch [17,29]. Finally, it was hypothesized that patients in the intervention group would take a more active part in the interaction.

\section{Methods}

\subsection{Design and sample}

Effects of the programme were measured in a pre-test post-test control group design. The experimental group included 24 nurses who had participated in the training and the control group consisted of 23 nurses who participated in the training later on. The nurses were working in two different settings: in a home care organisation and in a home for the elderly. All nurses who met the inclusion criteria, i.e. of having completed a basic nursing training and being involved in direct patient care activities, were asked to cooperate. As all subjects planned to participate in the training, assignment to experimental or control group was mostly on practical criteria. Two nurses in the experimental group and five nurses in the control group did not remain in the study until the last measurement. Reasons were: resignation $(n=3), \quad$ illness/pregnancy $\quad(n=3)$, change of job $(n=1)$. The effects of the training were determined on the basis of data from 40 nurses. Table 1 summarizes nurses' characteristics in both groups. There were no significant differences between experimental and control group with respect to the background characteristics.

\subsection{Procedure}

Prior to and 2 months after completing the training, videotaped data of nurse-patient interaction was collected. For that purpose, each participating nurse was followed for part of the day, during which about four nursing encounters were recorded. Nurses recruited the patients for this study. A few days prior to data collection, nurses informed their patients about the research, and asked patients to give informed written consent to allow the recording for research purposes. Very sick patients, patients suffering from dementia and terminally ill patients were excluded from participation. Very few home care patients refused to participate. In the home for the elderly, half of the sixty residents who were asked to participate did so during the pre-test. During the post-test, participation increased to $75 \%$. Nurses did not systematically inform the researchers about those patients who did not wish to cooperate, but they reported that there was no clear difference between the participating and non-participating residents. Moreover, the two groups of patients could be considered representative samples of the populations of patients in the community and in homes for the elderly, with regard to age and gender [29]. In total 241 patients participated. There were no significant differences in patient characteristics, between preand post-test (Table 2).

Before training, the intervention group recorded 87 and the control group 69 encounters. After training, the figures were 87 and 73, respectively. Each encounter was videotaped entirely using a manned camera. The encounters had a mean duration of $18 \mathrm{~min}$ (range 4.8-60.7). Of the pre-test sample, $20 \%$ of the encounters were dominated by psychosocial care and the remaining $80 \%$ of the visits, 
Table 1

Comparison between nurses in the experimental and control group with respect to background characteristics ${ }^{\mathrm{a}}$

\begin{tabular}{|c|c|c|c|c|}
\hline \multicolumn{2}{|l|}{ Background characteristics } & \multicolumn{3}{|c|}{ Participants in the study } \\
\hline & & $\begin{array}{l}\text { Experimental } \\
\text { group } \\
(n=21)\end{array}$ & $\begin{array}{l}\text { Control } \\
\text { group } \\
(n=19)\end{array}$ & Test \\
\hline Gender & $\begin{array}{l}\text { Female } \\
\text { Male }\end{array}$ & $\begin{array}{l}95.2 \% \\
4.8 \%\end{array}$ & $100 \%$ & \\
\hline Educational level $^{\mathrm{b}}$ & $\begin{array}{l}\text { Nurses } \\
\text { Auxiliary nurses }\end{array}$ & $\begin{array}{l}42.8 \% \\
57.1 \%\end{array}$ & $\begin{array}{l}31.6 \% \\
68.4 \%\end{array}$ & $\begin{array}{l}\chi^{2}=1.63 \\
\mathrm{df}=1 \\
P=0.20\end{array}$ \\
\hline Age in years & & 39.4 & 35.3 & $\begin{array}{l}t=1.64 \\
\mathrm{df}=37 \\
P=0.11\end{array}$ \\
\hline $\begin{array}{l}\text { Years of employment as } \\
\text { a nurse (years) } \\
\text { Number of nurses working in }\end{array}$ & & 17.0 & 14.5 & $\begin{array}{l}t=0.84 \\
\mathrm{df}=37 \\
P=0.41\end{array}$ \\
\hline & $\begin{array}{l}\text { (a) Home care } \\
\text { (b) Institutional care }\end{array}$ & $\begin{array}{l}52.4 \% \\
47.6 \%\end{array}$ & $\begin{array}{l}47.3 \% \\
52.6 \%\end{array}$ & $\begin{array}{l}\chi^{2}=0.17 \\
\mathrm{df}=1 \\
P=0.68\end{array}$ \\
\hline
\end{tabular}

\footnotetext{
${ }^{a}$ To test the differences in background characteristics $t$-tests and $\chi^{2}$ tests were used.

${ }^{\mathrm{b}}$ Nurses = Dutch higher professional education level, HBO or 3.5 years of in-service education; Auxiliary nurses $=$ Dutch secondary professional education level, MBO or 2.5 years of in-service education.
}

Table 2

Distribution of age, sex and duration of receiving nursing care of patients who took part in the study $(n=241)$

\begin{tabular}{|c|c|c|c|c|c|c|}
\hline & \multicolumn{3}{|l|}{ Pre-test } & \multicolumn{3}{|l|}{ Post-test } \\
\hline & Total & Home care & Home for the elderly & Total & Home care & Home for the elderly \\
\hline$n$ & 109 & $81(75 \%)$ & $28(25 \%)$ & 132 & $85(64 \%)$ & $47(36 \%)$ \\
\hline \multicolumn{7}{|l|}{ Gender } \\
\hline Female & $77(71 \%)$ & $54(67 \%)$ & $25(89 \%)$ & $100(76 \%)$ & $59(69 \%)$ & $41(87 \%)$ \\
\hline Male & $32(29 \%)$ & $27(33 \%)$ & $3(11 \%)$ & $32(24 \%)$ & $26(31 \%)$ & $6(13 \%)$ \\
\hline Mean age & 79 & 77 & 87 & 80 & 76 & 86 \\
\hline $\begin{array}{l}\text { Mean duration of } \\
\text { received nursing } \\
\text { care in months }\end{array}$ & 44 & 37 & 70 & 37 & 29 & 52 \\
\hline
\end{tabular}

involved hygiene or technical nursing care. During the post-test, these percentages were 30 and 70 , respectively.

\subsection{Assessment}

\subsubsection{Observations and analysis of communication}

Nurse-patient communication was measured by two independent observers, who were not informed about the experimental conditions. They used the CAMERA computer system [30], which is especially designed for coding behavioural interaction directly from video recordings.
The verbal communication process was analysed using an adapted version of Roter's Interaction Analysis System (RIAS) [31], adapted by CarisVerhallen et al. [32]. The system is widely used, has been shown to be reliable [33-36] and was relatively favourably judged in a comparative study [37]. In addition, RIAS is most suitable for our study, because it pays attention to socio-emotional and task-related communication.

The adapted version contains 24 verbal categories which were grouped into five clusters of more general communication behaviours [38]. These include: 
1. Social communication, containing social conversation that has no particular function in nursing activities, such as personal statements, small talk and banter.

2. Affective communication, containing verbal attentiveness, concern and empathy with the patient.

3. Communication that structures the encounter, involving utterances that indicate guidance and direction such as providing orientation and instruction, making requests for clarification, asking for understanding and asking for opinions.

4. Communication about nursing and health, containing all items with respect to nursing, health, medical or therapeutic topics.

5. Communication about lifestyle and feelings, containing all items with respect to lifestyle and emotions.

In addition to verbal communication, five nonverbal behaviours were observed which were considered to be essential for building rapport [17]: patient directed eyegaze, affirmative nodding, smiling, leaning forward and touch. Because touch is inherent in nursing activities, a distinction was made between instrumental touch, which is necessary in performing a task, and affective touch which expresses affection. Only the latter plays a role in rapport building.

The nonverbal categories were expressed as proportions. The total registered time in 'patient directed eyegaze', 'forward leaning', 'affective touch' and 'instrumental touch' was divided by the duration of time that nurse and patient were in sight. Similarly, the time span of 'nodding' and 'smiling' were divided by the time that the nurse's face was in sight.

In addition to the observation of specific nonverbal behaviours, the general affective impression of nurses' communication was rated on seven 6-point rating scales, measuring irritation, nervousness, assertiveness, interest, warmth, patronizing and involvement (1 low, 6 high) [31,32].

Following Henbest and Fehrsen [39], who noted that scoring only a part of a consultation was as reliable as scoring an entire consultation, preliminary assessments with observation periods of $5 \mathrm{~min}, 10$ min and the total length of the encounter were carried out on 48 encounters and compared. As 10-min observation periods proved to be very reliable when compared with the total observation time (mean Pearson's $r$ 0.91) [32,38], observation time was standardized to the first $10 \mathrm{~min}$. Interrater reliability for verbal and nonverbal communication behaviours was sufficient, ranging between 0.70 and 0.98 (Pearson's $r$ ) [29,38].

\subsubsection{Assessing the effects of training}

Before examining specific training effects, overall changes in nurses' communication behaviour were explored by analysing the five general verbal communication behaviours. These reveal information about the amount of affective and task-related communication and the conversation topics, i.e. on nursing and health or lifestyle and emotions.

In addition, several verbal composites were calculated, related to the hypotheses in the study. These included: the number of questions in general, openended questions and closed questions; a measure summing up all utterances of giving information and a measure for the number of counselling utterances and advice, reflecting the supportive attitude of the nurse. Besides, the amount of disagree and criticism were measured. Both verbal cluster measures and composites are expressed as proportional frequencies relating to the total number of utterances. A measure of nurses' verbal dominance was calculated by the mean speaking time in minutes. In addition to these verbal measures, the mean proportion of nonverbal categories and assessments on global affect ratings were investigated.

The patients active part in the interaction was assessed with verbal composite scores, that were comparable with those of the nurses. However, no distinction was made in type of questions. Furthermore, the category of 'counselling and advice' had a slightly different definition and referred to utterances in which patients formulated solutions to their own problems.

\subsection{Statistical analysis}

The data set in this study consists of two levels. The level of the encounter and the level of the nurse. The observations at the encounter level were expected to be explained by interventions at the nurse level [40]. A complicating factor in answering the research question was that the 316 encounters cannot be considered completely as independent observa- 
tions. As each individual nurse has her own behavioural style, it might be argued that the encounters of one nurse, on average, would resemble one another more than those of different nurses [12]. In an earlier study, [29] we calculated intra-class correlation coefficients to determine this interdependency. These coefficients reflect the proportion of total variance of an observation associated with the class (the nurse) to which it belongs. The magnitudes of intraclass correlations necessitated the use of a multilevel analysis. This type of analysis creates the option of analysing data at the encounter level, without disregarding the interdependency at the level of the nurses. Data were, therefore, analysed in hierarchical linear models, which were also controlled for type of nursing activity, as the latter had been shown previously [38] to be related to nurse communication. Contrast analyses were carried out to test for differences between the pre- and postmeasurements within the control and the experimental groups. In addition, mean pre-test post-test differ- ences in the experimental group were tested against mean pre-test post-test differences in the control group by means of interaction-tests. The analyses were performed with MLn software [41].

\section{Results}

\subsection{Nurses' verbal communication}

The mean proportions of verbal behaviour, calculated for the two different settings separately, are displayed in Tables 3 and 4. Contrast analyses were made between the scores of the trained nurses at the post-test and the other measurements. In both settings, we see minor alterations in the five communication behaviours (upper part of Tables 3 and 4), indicating that the general communication patterns did not change with different measurements. As regards the verbal composites, it appears that changes in the experimental group were most strong-

Table 3

Weighted mean proportions and standard errors of nurses' verbal communication and composites of nurses' verbal communication behaviours at pre- and post measurement, in the home care organisation

\begin{tabular}{|c|c|c|c|c|c|c|c|c|c|}
\hline \multirow[t]{3}{*}{ Variables } & \multicolumn{4}{|c|}{ Experimental group } & \multicolumn{4}{|c|}{ Control group } & \multirow[t]{3}{*}{$P^{\mathrm{a}}$} \\
\hline & \multicolumn{2}{|c|}{$\begin{array}{l}\text { Pre } \\
n=44 \\
\text { encounters }\end{array}$} & \multicolumn{2}{|c|}{$\begin{array}{l}\text { Post } \\
n=43 \\
\text { encounters }\end{array}$} & \multicolumn{2}{|c|}{$\begin{array}{l}\text { Pre } \\
n=31 \\
\text { encounters }\end{array}$} & \multicolumn{2}{|c|}{$\begin{array}{l}\text { Post } \\
n=35 \\
\text { encounters }\end{array}$} & \\
\hline & M & (S.E.) & M & (S.E.) & M & (S.E.) & M & (S.E.) & \\
\hline \multicolumn{10}{|c|}{ Verbal communication clusters } \\
\hline Social communication & 0.194 & $(0.037)$ & 0.186 & $(0.038)$ & 0.171 & $(0.046)$ & 0.202 & $(0.042)$ & 0.50 \\
\hline Affective communication & 0.357 & $(0.025)$ & 0.323 & $(0.026)$ & 0.331 & $(0.031)$ & 0.283 & $(0.028)$ & 0.60 \\
\hline $\begin{array}{l}\text { Communication that } \\
\text { structures the encounter }\end{array}$ & 0.120 & $(0.019)$ & 0.095 & $(0.019)$ & 0.130 & $(0.023)$ & 0.123 & $(0.021)$ & 0.50 \\
\hline $\begin{array}{l}\text { Communication nursing } \\
\text { and health care }\end{array}$ & 0.199 & $(0.030)$ & 0.267 & $(0.031)^{*}$ & 0.238 & $(0.038)$ & 0.278 & $(0.034)$ & 0.50 \\
\hline $\begin{array}{l}\text { Communication lifestyle } \\
\text { and feelings }\end{array}$ & 0.128 & $(0.019)$ & 0.123 & $(0.020)$ & 0.127 & $(0.024)$ & 0.112 & $(0.022)$ & 0.75 \\
\hline \multicolumn{10}{|l|}{ Verbal composites } \\
\hline Disagreement & 0.006 & $(0.002)$ & 0.002 & $(0.002)^{* *}$ & 0.004 & $(0.002)$ & 0.003 & $(0.002)$ & 0.30 \\
\hline Questions & 0.097 & $(0.014)$ & 0.113 & $(0.014)$ & 0.100 & $(0.017)$ & 0.095 & $(0.015)$ & 0.30 \\
\hline Closed questions & 0.086 & $(0.012)$ & 0.095 & $(0.012)$ & 0.086 & $(0.015)$ & 0.078 & $(0.014)$ & 0.35 \\
\hline Open-ended questions & 0.011 & $(0.003)$ & 0.019 & $(0.004)$ & 0.014 & $(0.004)$ & 0.017 & $(0.004)$ & 0.40 \\
\hline Information & 0.202 & $(0.023)$ & 0.262 & $(0.023)^{* *}$ & 0.244 & $(0.028)$ & 0.282 & $(0.026)$ & 0.50 \\
\hline Counselling and advice & 0.028 & $(0.004)$ & 0.014 & $(0.004)^{* *}$ & 0.020 & $(0.005)$ & 0.013 & $(0.005)$ & 0.30 \\
\hline Speaking time (min) & 2.64 & $(0.161)$ & 2.56 & $(0.165)$ & 1.98 & $(0.196)$ & 0.184 & $(0.181)$ & 0.45 \\
\hline
\end{tabular}

${ }^{a}$ Significance level based on interaction tests of mean pre-test post-test differences in experimental and control group.

Pre-test versus post-test: $* P \leq 0.05 ; * * P \leq 0.01$. 
Table 4

Weighted mean proportions and standard errors of nurses' verbal communication and composites of nurses' verbal communication behaviours at pre- and post measurement, in the home for the elderly

\begin{tabular}{|c|c|c|c|c|c|c|c|c|c|}
\hline \multirow[t]{3}{*}{ Variables } & \multicolumn{4}{|c|}{ Experimental group } & \multicolumn{4}{|c|}{ Control group } & \multirow[t]{3}{*}{$P^{\mathrm{a}}$} \\
\hline & \multicolumn{2}{|c|}{$\begin{array}{l}\text { Pre } \\
n=43 \\
\text { encounters }\end{array}$} & \multicolumn{2}{|c|}{$\begin{array}{l}\text { Post } \\
n=44 \\
\text { encounters }\end{array}$} & \multicolumn{2}{|c|}{$\begin{array}{l}\text { Pre } \\
n=38 \\
\text { encounters }\end{array}$} & \multicolumn{2}{|c|}{$\begin{array}{l}\text { Post } \\
n=38 \\
\text { encounters }\end{array}$} & \\
\hline & M & (S.E.) & M & (S.E.) & M & (S.E.) & M & (S.E.) & \\
\hline \multicolumn{10}{|c|}{ Verbal communication clusters } \\
\hline Social communication & 0.453 & $(0.054)$ & 0.523 & $(0.048)$ & 0.495 & $(0.057)$ & 0.536 & $(0.053)$ & 0.90 \\
\hline Affective communication & 0.265 & $(0.029)$ & 0.237 & $(0.026)$ & 0.234 & $(0.031)$ & 0.223 & $(0.029)$ & 0.80 \\
\hline $\begin{array}{l}\text { Communication that } \\
\text { structures the encounter }\end{array}$ & 0.069 & $(0.017)$ & 0.040 & $(0.015)^{*}$ & 0.084 & $(0.018)$ & 0.063 & $(0.017)$ & 0.25 \\
\hline $\begin{array}{l}\text { Communication nursing } \\
\text { and health care }\end{array}$ & 0.078 & $(0.023)$ & 0.058 & $(0.020)$ & 0.064 & $(0.024)$ & 0.034 & $(0.023)$ & 0.75 \\
\hline $\begin{array}{l}\text { Communication lifestyle } \\
\text { and feelings }\end{array}$ & 0.132 & $(0.019)$ & 0.144 & $(0.017)$ & 0.123 & $(0.020)$ & 0.144 & $(0.019)$ & 0.75 \\
\hline \multicolumn{10}{|l|}{ Verbal composites } \\
\hline Disagreement & 0.002 & $(0.002)$ & 0.001 & $(0.001)$ & 0.002 & $(0.002)$ & 0.001 & $(0.001)$ & 0.90 \\
\hline Questions & 0.069 & $(0.011)$ & 0.065 & $(0.010)$ & 0.049 & $(0.012)$ & 0.044 & $(0.011)$ & 0.90 \\
\hline Closed questions & 0.060 & $(0.010)$ & 0.053 & $(0.009)$ & 0.040 & $(0.011)$ & 0.032 & $(0.010)$ & 0.90 \\
\hline Open-ended questions & 0.009 & $(0.003)$ & 0.012 & $(0.003)$ & 0.009 & $(0.003)$ & 0.011 & $(0.003)$ & 0.75 \\
\hline information & 0.126 & $(0.020)$ & 0.129 & $(0.018)$ & 0.124 & $(0.021)$ & 0.122 & $(0.020)$ & 0.85 \\
\hline Counselling and advice & 0.016 & $(0.003)$ & 0.008 & $(0.003)^{* *}$ & 0.013 & $(0.003)$ & 0.009 & $(0.003)$ & 0.30 \\
\hline Speaking time (min) & 2.05 & $(0.176)$ & 2.19 & $(0.165)$ & 1.82 & $(0.191)$ & 2.09 & $(0.185)$ & 0.10 \\
\hline
\end{tabular}

${ }^{a}$ Significance level based on interaction tests of mean pre-test post-test differences in experimental and control group.

Pre-test versus post-test: * $P \leq 0.05$; ** $P \leq 0.01$.

ly evidenced in home care. Several significant contrasts emerged. At the post-test, trained nurses appeared to give significantly more information, in particular, information about topics on nursing and health care. They showed signs of disagreement, misunderstanding or criticism less often and gave less advice. When looking at the type of questions, it appeared that closed questions were used more frequently than open questions, which encourage patients to tell their story. In the experimental group, the number of open-ended questions had significantly increased, while the total number of questions remained more or less the same.

In the home for the elderly (Table 4) we see at post-measurement that experimental nurses made fewer utterances providing guidance and direction such as giving orientation and instruction, making requests for clarification and asking for understanding, compared with the pre-test. As in home care, the amount of counselling and advice had decreased in nurses in the experimental group. In the home for the elderly, no other differences were found between the scores of the control and the experimental group at the pre- and post-test.

In some instances Tables 3 and 4 show improvements of verbal communication of the untrained nurses, although the pre- and post-test differences do not reach statistical significance. Using open-ended questions, for instance, improved from 0.014 (pretest) to 0.017 (post-test) in untrained nurses in home care organizations (see Table 3 ). To account for the various improvements in the untrained group, no matter how small they are, we have tested the equality of the pre- and post-test differences in the trained nurses against the pre- and post-test differences in the untrained nurses. The $P$-values of these (interaction) tests are shown in the right-most column of Tables 3 and 4 . None of the test statistics reached statistical significance. This means, for example, that although the trained nurses in home care organizations improved in using open-ended questions 0.011 (pre-test) to 0.019 (post-test), their 
performance improved not significantly more than that of the untrained nurses. The same goes for all the verbal communication clusters and composites of Tables 3 and 4 . So, the positive changes we found in the experimental group cannot be attributed completely to the intervention.

\subsection{Nurses' nonverbal communication}

In home care, contrary to expectation, we see a decrease in two nonverbal behaviours in the experimental group (Table 5). Experimental nurses smiled to a lesser extent and leaned forward less frequently, after the training. These differences were not apparent in the control group. In the home for the elderly (Table 6) no effects with respect to the five nonverbal behaviours were found within the two groups.

In both settings, the experimental groups showed more changes in the global affect ratings than in specific nonverbal behaviours. In home care we see four significant differences in the experimental group, all in the direction expected. After training, nurses showed more interest in their patients, were warmer and more involved, and they behaved in a less patronizing way. Contrary to expectations, the control group shows also an increase in interest. Moreover this group shows another unexpected effect. The degree of nervousness is significantly lower at the post-test compared to the pre-test. This is possibly due to a high baseline score for nervousness at the pre-test, which was significantly higher, when compared with the other group. In the home for the elderly we see several significant changes in global affect ratings. Nurses in the experimental group were rated as more interested, involved and warm during the post-test. In addition, they were less patronizing. These changes were not found in the control group.

The right column of both Tables 5 and 6 shows the $P$-values of the (interaction) tests on the equality of the pre- and post-test differences of the trained nurses against the pre- and post-test differences of the untrained nurses. The results show that none of the tests reach statistical significance at 0.05 . Looking at the $P$-values between 0.05 and 0.10 for trends,

Table 5

Weighted mean proportions and standard errors for nonverbal communication at pre- and post measurement, in the home care organisation

\begin{tabular}{|c|c|c|c|c|c|c|c|c|c|}
\hline \multirow[t]{3}{*}{ Variables } & \multicolumn{4}{|c|}{ Experimental group } & \multicolumn{4}{|c|}{ Control group } & \multirow[t]{3}{*}{$P^{\mathrm{a}}$} \\
\hline & \multicolumn{2}{|c|}{$\begin{array}{l}\text { Pre } \\
n=44 \\
\text { encounters }\end{array}$} & \multicolumn{2}{|c|}{$\begin{array}{l}\text { Post } \\
n=43 \\
\text { encounters }\end{array}$} & \multicolumn{2}{|c|}{$\begin{array}{l}\text { Pre } \\
n=31 \\
\text { encounters }\end{array}$} & \multicolumn{2}{|c|}{$\begin{array}{l}\text { Post } \\
n=35 \\
\text { encounters }\end{array}$} & \\
\hline & M & (S.E.) & M & (S.E.) & M & (S.E.) & M & (S.E.) & \\
\hline \multicolumn{10}{|l|}{ Nonverbal behaviour } \\
\hline Eye gaze & 0.624 & $(0.042)$ & 0.644 & $(0.043)$ & 0.592 & $(0.053)$ & 0.546 & $(0.046)$ & 0.30 \\
\hline Affirmative head nodding & 0.046 & $(0.005)$ & 0.054 & $(0.005)$ & 0.036 & $(0.006)$ & 0.036 & $(0.006)$ & 0.30 \\
\hline Smiling & 0.024 & $(0.003)$ & 0.015 & $(0.003)^{*}$ & 0.015 & $(0.004)$ & 0.011 & $(0.003)$ & 0.30 \\
\hline Forward leaning & 0.022 & $(0.006)$ & 0.003 & $(0.005)^{*}$ & 0.014 & $(0.008)$ & 0.004 & $(0.007)$ & 0.40 \\
\hline Affective touch & 0.004 & $(0.003)$ & 0.006 & $(0.003)$ & 0.004 & $(0.003)$ & 0.004 & $(0.003)$ & 0.70 \\
\hline \multicolumn{10}{|l|}{ Global affect ratings } \\
\hline Anger/irritation & 1.04 & $(0.074)$ & 1.05 & $(0.075)$ & 1.00 & $(0.093)$ & 1.12 & $(0.082)$ & 0.20 \\
\hline Nervousness & 1.07 & $(0.144)$ & 0.99 & $(0.148)$ & 1.34 & $(0.178)$ & 0.97 & $(0.162)^{*}$ & 0.15 \\
\hline Dominance & 2.92 & $(0.189)$ & 2.68 & $(0.194)$ & 2.93 & $(0.234)$ & 2.85 & $(0.213)$ & 0.50 \\
\hline interest & 4.34 & $(0.186)$ & 4.66 & $(0.190)^{* *}$ & 4.09 & $(0.221)$ & 4.58 & $(0.208)^{*}$ & 0.40 \\
\hline Warmth & 3.90 & $(0.222)$ & 4.64 & $(0.227)^{* * *}$ & 3.79 & $(0.266)$ & 4.14 & $(0.249)$ & 0.10 \\
\hline Patronizing & 1.93 & $(0.157)$ & 1.31 & $(0.162)^{* * *}$ & 1.39 & $(0.194)$ & 1.09 & $(0.178)$ & 0.15 \\
\hline Involved attitude & 3.78 & $(0.173)$ & 4.23 & $(0.178)^{* *}$ & 3.54 & $(0.214)$ & 3.90 & $(0.196)^{*}$ & 0.70 \\
\hline $\begin{array}{l}\text { Mean duration encounter } \\
(\mathrm{min})\end{array}$ & 27.1 & (2.6) & 23.9 & $(2.6)$ & 22.8 & $(3.2)$ & 24.7 & (2.8) & 0.20 \\
\hline
\end{tabular}

${ }^{a}$ Significance level based on interaction tests of mean pre-test post-test differences in experimental and control group.

Pre-test versus post-test: $* P \leq 0.05 ; * * P \leq 0.01 ; * * * P \leq 0.001$. 
Table 6

Weighted mean proportions and standard errors for nonverbal communication at pre- and post measurement, in the home for the elderly

\begin{tabular}{|c|c|c|c|c|c|c|c|c|c|}
\hline \multirow[t]{3}{*}{ Variables } & \multicolumn{4}{|c|}{ Experimental group } & \multicolumn{4}{|c|}{ Control group } & \multirow[t]{3}{*}{$P^{\mathrm{a}}$} \\
\hline & \multicolumn{2}{|c|}{$\begin{array}{l}\text { Pre } \\
n=43 \\
\text { encounters }\end{array}$} & \multicolumn{2}{|c|}{$\begin{array}{l}\text { Post } \\
n=44 \\
\text { encounters }\end{array}$} & \multicolumn{2}{|c|}{$\begin{array}{l}\text { Pre } \\
n=38 \\
\text { encounters }\end{array}$} & \multicolumn{2}{|c|}{$\begin{array}{l}\text { Post } \\
n=38 \\
\text { encounters }\end{array}$} & \\
\hline & $\mathrm{M}$ & (S.E.) & M & (S.E.) & M & (S.E.) & M & (S.E.) & \\
\hline \multicolumn{10}{|l|}{ Nonverbal behaviour } \\
\hline Eye gaze & 0.749 & $(0.050)$ & 0.796 & $(0.044)$ & 0.759 & $(0.054)$ & 0.758 & $(0.051)$ & 0.5 \\
\hline $\begin{array}{l}\text { Affirmative } \\
\text { head nodding }\end{array}$ & 0.053 & $(0.008)$ & 0.054 & $(0.007)$ & 0.061 & $(0.008)$ & 0.053 & $(0.008)$ & \\
\hline Smiling & 0.030 & $(0.007)$ & 0.028 & $(0.007)$ & 0.031 & $(0.008)$ & 0.042 & $(0.008)$ & 0.25 \\
\hline Forward leaning & 0.034 & $(0.012)$ & 0.017 & $(0.011)$ & 0.017 & $(0.013)$ & 0.008 & $(0.012)$ & 0.60 \\
\hline Affective touch & 0.054 & $(0.018)$ & 0.029 & $(0.015)$ & 0.013 & $(0.018)$ & 0.023 & $(0.018)$ & 0.10 \\
\hline \multicolumn{10}{|l|}{ Global affect ratings } \\
\hline Anger/irritation & 1.00 & $(0.027)$ & 1.04 & $(0.024)$ & 0.99 & $(0.029)$ & 1.02 & $(0.027)$ & 0.60 \\
\hline Nervousness & 1.01 & $(0.108)$ & 1.10 & $(0.102)$ & 1.06 & $(0.118)$ & 1.25 & $(0.114)^{*}$ & 0.50 \\
\hline Dominance & 2.52 & $(0.142)$ & 2.50 & $(0.125)$ & 2.24 & $(0.149)$ & 2.43 & $(0.139)$ & 0.40 \\
\hline Interest & 4.41 & $(0.165)$ & 4.89 & $(0.154)^{* *}$ & 4.27 & $(0.179)$ & 4.42 & $(0.173)$ & 0.08 \\
\hline Warmth & 4.36 & $(0.187)$ & 4.87 & $(0.176)^{* * *}$ & 4.36 & $(0.204)$ & 4.51 & $(0.197)$ & 0.07 \\
\hline Patronizing & 1.42 & $(0.154)$ & 1.17 & $(0.145)^{*}$ & 1.48 & $(0.168)$ & 1.24 & $(0.162)$ & 0.90 \\
\hline Involved attitude & 4.02 & $(0.167)$ & 4.31 & $(0.156)^{*}$ & 4.09 & $(0.181)$ & 4.18 & $(0.174)$ & 0.30 \\
\hline $\begin{array}{l}\text { Mean duration encounter } \\
\text { (min) }\end{array}$ & 15.8 & (1.7) & 14.2 & $(1.5)$ & 12.2 & $(1.8)$ & 13.2 & $(1.7)$ & 0.25 \\
\hline
\end{tabular}

${ }^{a}$ Significance level based on interaction tests of mean pre-test post-test differences in experimental and control group.

Pre-test versus post-test: *P $\leq 0.05 ; * * P \leq 0.01 ; * * * P \leq 0.001$.

reveals that trained nurses improved more in showing interest and warmth than the untrained nurses, but only in the home for the elderly (Table 6). All of the other nonverbal behaviour variables and global affect ratings of the trained nurses did not improve significantly more than those of the untrained nurses.

\subsection{Patients' share in the interaction}

In home care, patients who received care from trained nurses showed less disagreement during the interaction (Table 7). Moreover, they gave more information about nursing and health topics and their lifestyle. Finally, patients of trained nurses more often came up with ideas of their own and solutions to their problems. These differences were not apparent in the control group.

In the home for the elderly no effects were found, with respect to patients' share in the interaction (Table 8). Contrary to our expectations, the speaking time of patients in the control group increased.
Finally, it was tested whether the patients' share in encounters of trained nurses changed more than patients' share in encounters of untrained nurses. The right column of Tables 7 and 8 shows that none of these differences reach statistical significance, indicating that patients receiving care from trained nurses, changed in the same way as patients receiving care from the untrained nurses.

\section{Discussion}

The aim of this evaluation study was to explore the effects of a communication training, based on Video Interaction Analysis. Findings within groups indicate that communication patterns do indeed change. This counts especially for the nurses in home care. We found that nurse communication after training was more facilitating. Nurses showed less disagreement, used more open-ended questions and gave more information. Furthermore, these nurses 
Table 7

Weighted mean proportions and standard errors for patients verbal communication composites at pre- and post measurement, in the home care organisation

\begin{tabular}{|c|c|c|c|c|c|c|c|c|c|}
\hline \multirow[t]{3}{*}{ Variables } & \multicolumn{4}{|c|}{ Experimental group } & \multicolumn{4}{|c|}{ Control group } & \multirow[t]{3}{*}{$P^{\mathrm{a}}$} \\
\hline & \multicolumn{2}{|c|}{$\begin{array}{l}\text { Pre } \\
n=44 \\
\text { encounters }\end{array}$} & \multicolumn{2}{|c|}{$\begin{array}{l}\text { Post } \\
n=43 \\
\text { encounters }\end{array}$} & \multicolumn{2}{|c|}{$\begin{array}{l}\text { Pre } \\
n=31 \\
\text { encounters }\end{array}$} & \multicolumn{2}{|c|}{$\begin{array}{l}\text { Post } \\
n=35 \\
\text { encounters }\end{array}$} & \\
\hline & $\mathrm{M}$ & (S.E.) & $\mathrm{M}$ & (S.E.) & M & (S.E.) & $\mathrm{M}$ & (S.E.) & \\
\hline \multicolumn{10}{|l|}{ Verbal composites } \\
\hline Disagreement & 0.016 & $(0.003)$ & 0.004 & $(0.003)^{* * *}$ & 0.013 & $(0.004)$ & 0.005 & $(0.004)^{*}$ & 0.60 \\
\hline Questions & 0.007 & $(0.003)$ & 0.006 & $(0.003)$ & 0.011 & $(0.004)$ & 0.008 & $(0.004)$ & 0.70 \\
\hline information & 0.550 & $(0.033)$ & 0.656 & $(0.034)^{* * *}$ & 0.566 & $(0.041)$ & 0.623 & $(0.037)$ & 0.30 \\
\hline Counselling and advice & 0.001 & $(0.001)$ & 0.004 & $(0.001)^{* * *}$ & 0.001 & $(0.001)$ & 0.001 & $(0.001)$ & 0.12 \\
\hline Speaking time (min) & 4.32 & $(0.266)$ & 3.97 & $(0.270)$ & 3.57 & $(0.334)$ & 3.53 & $(0.295)$ & 0.50 \\
\hline
\end{tabular}

${ }^{a}$ Significance level based on interaction tests of mean pro-test post-test differences in experimental and control group.

Pre-test versus post-test: $* P \leq 0.05 ; * * P \leq 0.01 ; * * * P \leq 0.001$.

Table 8

Weighted mean proportions and standard errors for patients verbal communication composites at pre- and post measurement, in the home for the elderly

\begin{tabular}{|c|c|c|c|c|c|c|c|c|c|}
\hline \multirow[t]{3}{*}{ Variables } & \multicolumn{4}{|c|}{ Experimental group } & \multicolumn{4}{|c|}{ Control group } & \multirow[t]{3}{*}{$P^{\mathrm{a}}$} \\
\hline & \multicolumn{2}{|c|}{$\begin{array}{l}\text { Pre } \\
n=43 \\
\text { encounters }\end{array}$} & \multicolumn{2}{|c|}{$\begin{array}{l}\text { Post } \\
n=44 \\
\text { encounters }\end{array}$} & \multicolumn{2}{|c|}{$\begin{array}{l}\text { Pre } \\
n=38 \\
\text { encounters }\end{array}$} & \multicolumn{2}{|c|}{$\begin{array}{l}\text { Post } \\
n=38 \\
\text { encounters }\end{array}$} & \\
\hline & M & (S.E.) & M & (S.E.) & M & (S.E.) & M & (S.E.) & \\
\hline \multicolumn{10}{|l|}{ Verbal composites } \\
\hline Disagreement & 0.005 & $(0.003)$ & 0.003 & $(0.003)$ & 0.003 & $(0.003)$ & 0.008 & $(0.003)$ & 0.15 \\
\hline Questions & 0.004 & $(0.005)$ & 0.003 & $(0.004)$ & 0.006 & $(0.005)$ & 0.008 & $(0.005)$ & 0.70 \\
\hline Information & 0.359 & $(0.044)$ & 0.373 & $(0.039)$ & 0.364 & $(0.047)$ & 0.354 & $(0.044)$ & 0.70 \\
\hline Counselling and advice & 0.000 & $(0.000)$ & 0.001 & $(0.000)$ & 0.000 & $(0.000)$ & 0.001 & $(0.000)$ & 0.90 \\
\hline Speaking time (min) & 4.26 & $(0.300)$ & 4.38 & $(0.269)$ & 3.67 & $(0.319)$ & 4.47 & $(0.300)^{*}$ & 0.40 \\
\hline
\end{tabular}

${ }^{a}$ Significance level based on interaction tests of mean pre-test post-test differences in experimental and control group.

Pre-test versus post-test: $* P \leq 0.05$.

were rated as more interested and involved, warmer, and less patronizing. Although the training is primarily directed at nurse communication, the changes in interaction extended to the patients as well. Patients of trained nurses showed a decrease in disagreement, they gave more information and produced their own solutions more often.

The effects in the home for the elderly were less convincing and mainly limited to the emotional tone during the encounter, assessed on the global affect scales. After the training nurses showed a more involved and warmer attitude. As regards verbal communication categories, we see effects in the amount of counselling and advice.

It is not completely clear how differences in both settings can be clarified. As we concluded in an earlier study, the nurses in the two settings did not differ with respect to attitudes towards elderly people, therapeutic attitude, job satisfaction or personal characteristics $[32,38]$. A possible explanation might be the characteristics of the setting. In institutional care, daily activities are more tightly scheduled than in home care. Nurses and patients on the ward have to do with the ward culture and daily routine. In 
home care, patients live independently, are visited by their nurse and ward characteristics do not influence nurse-patient interaction. Perhaps, this independence is conducive to the implementation of the communication skills learned.

There were some other unexpected findings that need to be clarified. Firstly, we hypothesized that nurses would express fewer dominant behaviours. No significant effects were found in this respect; although, in the home care setting, nurses did show a decrease in patronizing behaviour. Trained nurses in the home for the elderly showed a decrease in the type of communication that structures encounters. The characteristics of this type of communication meant that we could interpret this effect positively. A majority of utterances in this cluster are orientating and instructional remarks like 'let's start' 'you can go to the bathroom' and asking for understanding or clarification. Use of these utterances structures the interaction from the nurses' point of view. In that sense, a decrease in this kind of communication might indicate a decrease in dominance. Similarly, the decrease in counselling and advice, which we found in the experimental groups in both settings could be interpreted as an effect in the desired direction. These kind of utterances do not always support patients to find their own answers, and if patients not specifically ask for advice they can even be patronizing and dependency creating [10].

Secondly, trained nurses in home care showed a significant decrease in smiling and leaning forward, which could not be attributed to different types of nursing care provided, because the scores were controlled for this. In a sense, these results are disappointing because these behaviours are considered to be important in establishing a good relationship with the patient $[16,17]$. Smiling may be one of the most important characteristics of a nurse who wishes to establish good rapport with patients $[17,42]$, while leaning forward is a sign of attention and conveys warmth and friendliness [43].

This brings up the important issue of conceptual validity. Actually, nonverbal behaviour is more complex than we suggested in this paper. Some nonverbal behaviours are multi-interpretable. For instance leaning forward combined with eye gaze direction can both indicate paying attention and dominance [42]. Smiling can convey friendliness but also cynicism or arrogance $[17,18]$. To observe these behaviours in a more valid way, one should have more than one video camera and record from different angles. The use of such methods is not possible in nursing practice, but is restricted to experimental arrangements.

Another point of concern is a possible selection bias, as a result of the fact that nurses recruited the patients for the study themselves. This procedure of patient selection may have resulted in a bias of the effects, because nurses might have selected, with whom they were getting on well together. However, the methods were similar for experimental and control group, so both groups were advantaged equally much.

Apart from questions of selection bias, there was a limitation in the study concerning the quasi-experimental design. The results showed that the nurses in the experimental group changed significantly on several scores. This was especially true for nurses in home care. When looking at the control group, there were also changes in the desired direction, although mostly non-significant. Changes in communication patterns in both conditions may not only be due to the intervention, but also to participating in the project. All participating nurses had basic nurse training and may be expected to have knowledge on effective communication in nursing. The control nurses were exposed twice to video measurements together with the experimental group, they however had no training. The possibility of contamination between groups, the effect of video-recording and knowing that it has something to do with communication could have targeted earlier input on communication, leading to adaptations in behaviour in both conditions. When aiming to draw conclusions on the effect of the intervention per se, a comparison should be made between differences in the experimental group and the control group. Doing this, we were confronted with the problem that observations at the encounter level were used to measure effects of an intervention at the nurse level. For each nurse a number of three or four encounters was videotaped in the pre-test and the post-test phase of the study. The encounters were characterized by heterogeneity, meaning that at pre- and post measurement different patients were involved and also different types of care were concerned. In the multi level model we 
corrected for interdependency on nurses level and types of encounters. Still there was a lot of variation for which correction was not possible. These circumstances did not allow us to calculate differences between pre-test and post-test scores in the experimental and control group, which is the traditional method in a design with repeated measures (MANOVA). To address this problem we tested mean differences between pre- and post-test in the experimental group against mean differences in the control group by means of interaction-tests. This method failed to demonstrate any significant difference in change between the experimental and control group. Only some trends in the desired direction were found. Compared to the traditional approach the interaction tests seemed to be less powerful to detect significant between-group differences.

Subsequently, conclusions on the effects in the experimental group should be taken with caution. On the basis of systematic observations of nurses' verbal and nonverbal behaviour, we may say that there were some interesting results which might be induced by Video Interaction Analysis training, especially in the home care setting. Yet, due to limitations in research methods and study design the evidence is not strong enough as a proof.

Although this article only provides information about changes in communication behaviour, it was also found that the trainees assessed the training course positively on most counts [28]. They considered the educational method appropriate for learning communication skills and evaluated the training method as meaningful and relevant to daily nursing practice. Summing up these findings, it may be concluded that training based on Video Interaction Analysis is suitable when targeting change in the communicative behaviour of nurses in the care of the elderly. Effects of the training method should be replicated in a randomized controlled design, using larger sample sizes.

\section{Acknowledgements}

This research project is partly financed by the Dutch Ministry of Health, Welfare \& Sport, Department for Policy on the Elderly. The authors gratefully acknowledge the assistance of Peter M.M.
Spreeuwenberg, MSc, and Jan J. Kerssens, PhD, NIVEL Foundation Utrecht, in the statistical analysis of the study.

\section{References}

[1] Nolan M, Grant G, Nolan J. Busy doing nothing: Activity and interaction levels amongst differing populations of elderly patients. J Adv Nurs 1995;22:528-38.

[2] Salmon P. Interactions of nurses with elderly patients: relationship to nurses attitudes and to formal activity periods. J Adv Nurs 1993;18:14-9.

[3] Armstrong-Esther CA, Sandilands ML, Miller D. Attitudes and behaviours of nurses towards the elderly in an acute care setting. J Adv Nurs 1989;14:34-41.

[4] Armstrong-Esther CA, Browne KD, McAfee JG. Elderly patients: still clean and sitting quietly. J Adv Nurs 1994;19:264-71.

[5] Macleod-Clark J. Nurse-patient communication: an analysis of conversations from surgical wards. In: Wilson-Barnett J, editor, Nursing research: ten studies in patient care. Chichester: Wiley, 1983.

[6] Waters KR. Getting dressed in the early morning: styles of staff/patient interaction on rehabilitation hospital wards for elderly people. J Adv Nurs 1994;19:239-48.

[7] de Wilde I, de Bot K. Taal van verzorgenden tegen ouderen in een psycho-geriatrisch verpleeghuis (Language in nursing the elderly in a psycho geriatric nursing home). Tijdschr Gerontol Geriatr 1989;20:97-100.

[8] Bouchard Ryan E, Hamilton JM, Kwong See. Patronizing the old: How do younger and older adults respond to babytalk in the nursing home? Int $\mathrm{J}$ Aging Hum Dev 1994;39:21-32.

[9] Bouchard Ryan E, Maclean M, Orange JB. Inappropriate accommodation to elders: inferences about nonverbal correlates. Int J Aging Hum Dev 1994;39:273-91.

[10] Hewison A. Nurses power in interactions with patients. J Adv Nurs 1995;21:75-82.

[11] Cans GJ. Laten praten: een onderzoek naar opvoedingsondersteuning op het consultatiebureau (Let's talk: an investigation to parent support on the consultation office). Utrecht: SWP, 1997.

[12] Bensing JM, Kerssens JJ, van der Pasch M. Patient-directed gaze as a tool for discovering and handling psychosocial problems in general practice. $J$ Nonverb Behav 1995;19:223-43.

[13] Mehrabian A. Silent messages. Belmont, CA: Wadsworth, 1981.

[14] Roter DL, Hall JA. Doctors talking to patients/patients talking with doctors: Improving communication in medical visits. Westport, CT: Auburn House, 1992.

[15] Strecher VJ. Improving physician-patient interactions: a review. Patient Couns Health Educ 1983;4:129-36.

[16] Caris-Verhallen WMCM, Kerkstra A, Bensing JM. The role 
of communication in nursing care for the elderly, a review of the literature. J Adv Nurs 1997;25:915-33.

[17] Heintzman M, Leathers DG, Parrott RL, Cairns III AB. Nonverbal rapport-building behaviors effect on perceptions of a supervisor. Manag Commun Q 1993;7:181-208.

[18] Vrugt A. Betekenistoekenning aan nonverbale communicatie (Interpretation of nonverbal communication). $\mathrm{PhD}$ dissertation. Amsterdam: University of Amsterdam, 1983.

[19] Burgoon K. Nonverbal signals. In: Knapp ML, Miller GR, editors, Handbook of interpersonal communication, 2nd ed. Thousand Oaks, CA: Sage, 1994.

[20] de Wever MK. Nursing home patients perception of nurses affective touching. J Psychol 1977;96:163-71.

[21] McCann K, McKenna HP. An examination of touch between nurses and elderly patients in a continuing care setting in Northern Ireland. J Adv Nurs 1992;18:838-46.

[22] Moore JR, Gilbert DA. Elderly residents: perceptions of nurses comforting touch. J Gerontol Nurs 1995;21:6-13.

[23] O'Connor FW, Devine EC, Cook TD, Wenk VA, Curtin TR. Enhancing surgical nurses patient education: development and evaluation of an intervention. Patient Educ Couns 1990;16:7-20.

[24] Cox J, Mulholland H. An instrument for assessment of videotapes of general practitioners performance. Br Med $\mathrm{J}$ 1993;306:1043-6.

[25] Wilkinson S. Factors which influence how nurses communicate with cancer patients. J Adv Nurs 1991;16:677-88.

[26] Parathian AR, Taylor F. Can we insulate trainee nurses from exposure to bad practice? A study of role play in communicating bad news to patients. J Adv Nurs 1993;18:801-7.

[27] Heaven CM, Maguire P. Training hospice nurses to elicit patient concerns. J Adv Nurs 1996;23:280-6.

[28] Etten GP. Project Deskundigheidsbevordering: verslag van een experiment (Project expertness promotion: report of an experiment). 's-Hertogenbosch: Kruiswerk de Bossche Meierij, 1997.

[29] Caris-Verhallen WMCM, Kerkstra A, Bensing JM. Nonverbal behaviour in nurse-elderly patient communication. J Adv Nurs 1999;29:808-18.

[30] lec ProGAMMA. User manual CAMERA: a system for collecting and correcting behavioral data. Groningen: lec ProGAMMA, 1994.
[31] Roter D. The Roter method of interaction process analysis. Baltimore: Johns Hopkins University Press, 1989.

[32] Caris-Verhallen W.M.C.M. De Gruijter IM, Kerkstra A. De kwaliteit van de communicatie tussen verplegenden en oudere cliënten (Quality of communication between nurses and elderly people). Utrecht: NIVEL, 1997.

[33] van Dulmen AM, Verhaak PFM, Bib HJG. Shifts in doctorpatient communication during a series of outpatient consultations in non-insulin-dependent diabetes mellitus. Patient Educ Couns 1997;30:227-37.

[34] van den Brink-Muinen A. Gender, health and health care in general practice: A comparison between women?s health care and regular health care. Utrecht: NIVEL, 1996.

[35] de Gruyter I, Schirm M. Communicatie met oudere patiënten (Communicating with elderly patients). Master thesis. Utrecht: University of Utrecht, 1995.

[36] Bensing JM. Doctor-patient communication and the quality of care. Utrecht: NIVEL, 1991.

[37] Inui TS, Carter WB, Kukull WA, Haigh VH. Outcome-based doctor-patient interaction analysis. Med Care 1982;20:53549.

[38] Caris-Verhallen WMCM, Kerkstra A, Bensing JM. Nurseelderly patient communication home care and institutional care. Int J Nurs Stud 1998;35:95-108.

[39] Henbest RJ, Fehrsen GS. Patient-centredness: Is it applicable outside the West? Its measurement and effect on outcomes. Fam Pract 1992;9:311-7.

[40] Hulsman RL. Communication skills of medical specialists in oncology: development and evaluation of a computer assisted instruction program. Utrecht: NIVEL, 1998.

[41] Rasbash J, Woodhouse G. MLn command reference, version 1.0, multilevel models project. London: Institute of Education, University of London, 1995.

[42] Schabracq MJ. Betrokkenheid en onderlinge gelijkheid in sociale interacties (Involvement and equality in social interactions). PhD dissertation. Amsterdam: University of Amsterdam, 1987.

[43] Reece M, Whitman R. Expressive movements, warmth and verbal reinforcement. J Abnorm Soc Psychol 1962;64:234-6. 